\title{
Quantitative mRNA expression analysis of selected genes in patients with early-stage hypothyroidism induced by treatment with iodine-131
}

\author{
KUN GUO ${ }^{1}$, RUI GAO ${ }^{1}$, YAN YU², WEIXIAO ZHANG ${ }^{1}$, YUXUAN YANG ${ }^{2}$ and AIMIN YANG ${ }^{1}$ \\ ${ }^{1}$ Department of Nuclear Medicine, The First Affiliated Hospital of Xi'an Jiaotong University College of Medicine; \\ ${ }^{2}$ Department of Public Health, Medical College of Xi'an Jiaotong University, Xi'an, Shaanxi 710061, P.R. China
}

Received December 3, 2014; Accepted August 20, 2015

DOI: $10.3892 / \mathrm{mmr} .2015 .4350$

\begin{abstract}
The present study aimed to investigate the molecular markers indicative of early-stage hypothyroidism induced by treatment with iodine-131, in order to assist in further investigations of radio iodine-induced hypothyroidism. A total of 59 patients diagnosed with hyperthyroidism (male/female, 16/43; median age, 46.4 years) and 27 healthy subjects (male/female, $7 / 21$; median age, 44.6 years) were included in the present study. All patients were treated with appropriate doses of iodine-131 and, three months following treatment, the patients were subdivided into two groups: A group with early-stage hypothyroidism symptoms, and a group with non-early-stage hypothyroidism, including euthyroid patients and patients remaining with hyperthyroidism. Tissue samples from the patients and healthy subjects were collected by fine needle biopsies, and the mRNA expression levels of B-cell lymphoma 2 (Bcl-2), nuclear factor (NF)- $\mathrm{B}, \mathrm{Ku} 70$, epidermal growth factor receptor (EGFR), early growth response 1 (Egr-1), TP53 and ataxia telangiectasia mutated were analyzed using reverse transcription-quantitative polymerase chain reaction prior to iodine-131 treatment. The association of the variation of target genes with susceptibility to early-stage hypothyroidism was analyzed. Compared with normal subjects, the mRNA expression levels of Ku70 (0.768, vs. 3.304, respectively; $\mathrm{P}<0.001)$ and EGFR (0.859, vs. 1.752, respectively; $\mathrm{P}<0.05)$ were significantly higher, whereas those of NF- $\kappa \mathrm{B}(0.884$, vs. 0.578 ,
\end{abstract}

Correspondence to: Dr Aimin Yang, Department of Nuclear Medicine, The First Affiliated Hospital of Xi'an Jiaotong University College of Medicine, 277 Yanta West Road, Xi'an, Shaanxi 710061, P.R. China

E-mail: yangaimin@mail.xjtu.edu.cn

Ms. Yan Yu, Department of Public Health, Medical College of Xi'an Jiaotong University, 76 West Yanta Road, Xi'an, Shaanxi 710061, P.R. China

E-mail: yuyan@mail.xjtu.edu.cn

Key words: radioiodine, hyperthyroidism, early-stage hypothyroidism, B cell lymphoma 2, early growth response 1 respectively; $\mathrm{P}<0.05)$ and $\mathrm{Bcl}-2$ (1.235, vs. 0.834, respectively; $\mathrm{P}<0.05)$ were lower in the hyperthyroid patients. Following treatment with iodine-131, 30 of the $59(50.8 \%)$ patients with hyperthyroidism were diagnosed with early-stage hypothyroidism, and in the early-stage hypothyroidism group, the mRNA expression levels of Bcl-2 were significantly decreased $(\mathrm{P}<0.05)$, whereas those of Egr-1 $(\mathrm{P}<0.05)$ were significantly increased, compared with the non-early-stage hypothyroidism group. The association between the changes in the expression levles of Bcl-2 and Egr-1 and susceptibility to early-stage hypothyroidism was supported by multivariate regression analysis. No significant changes in the expression levels of the other target genes were detected. The opposing changes in the mRNA expression levels of Bcl-2 and Egr-1 in patients with early-stage hypothyroidism indicates their potential as prognostic markers of early-stage hypothyroidism induced by iodine-131 treatment.

\section{Introduction}

Hyperthyroidism is a form of thyrotoxicosis characterized by inappropriately high levels of thyroid hormones synthesized and secreted by the thyroid (1). Hyperthyroidism is a common endocrine disorder, which affects $0.5-2 \%$ of the population (2). Although hyperthyroidism is not life threatening, untreated hyperthyroidism can lead to hypertension, heart failure and bone mass loss, as well as an increase in birth defects if the patient is pregnant (3). The pathogenic mechanisms underlying hyperthyroidism are complex and multifactorial, however, several causes, including autoimmune defects, genetic predisposition and environmental factors have been well recognized (4). Despite the complexity of the initiation and development of hyperthyroidism, radioiodine therapy (RAIT) is currently the most common method for the treatment of hyperthyroidism in clinical settings due to its safety, effectiveness and low cost $(5,6)$. RAIT is based on short-range $\beta$ radiation from radioactive iodine-131, which destroys part of the thyroid gland, but retains a certain quantity of thyroid tissue (7). However, it has long been observed that hypothyroidism is one of the major side effects of RAIT, which poses additional risk to the patient. Previous studies have reported that hypothyroidism arises in $25-40 \%$ of patients who are 
treated with large doses of radioiodine (8-10), however, fewer investigations have been performed to examine the diagnostic markers and the potential pathological mechanisms, which drive the development of hypothyroidism in certain susceptible patients following RAIT. Due to the similarity of the ionization radiation used in cancer treatment, the present study hypothesized that cellular signaling pathways mediating radiosensitivity and radioresistance may be associated with the development of hypothyroidism.

Radiotherapy is one of the major therapeutic strategies for the treatment of human malignant tumors, however, a small number of cells are able to survive and gradually proliferate, reforming tumors with higher resistance to irradiation (11). Extensive investigations have demonstrated that multiple signal transduction signaling pathways, including cell proliferation, apoptosis/anti-apoptosis and DNA damage response are associated with radioresistance and radiosensitivity (12). Patients with ataxia telangiectasia are highly sensitive to irradiation due to a deficiency of the ataxia-telangiectasia mutated (ATM) protein (12), a critical factor of the DNA double strand break repair signaling pathway. Another example is epidermal growth factor receptor (EGFR), which is frequently overexpressed in human tumors, and high expression levels of EGFR are correlated with radioresistance $(13,14)$. To sensitize tumor cells to radiation, numerous drugs have been designed and developed to target proteins, which are essential for cell survival, in order to improve the prognosis of patients with cancer (15). Since RAIT is an irradiation-based treatment, it is possible that functional factors, which are involved in cellular resistance or sensitivity, may contribute to susceptibility to hypothyroidism following RAIT, and the identification of these functional factors may improve current understanding of the molecular mechanism underlying RAIT-induced hypothyroidism, and improve diagnostic and treatment methods. To the best of our knowledge, the present study is the first to screen potential molecular markers of hypothyroidism in patients by quantitatively analyzing the mRNA expression levels of selected genes, including EGFR, ATM, TP53, Ku70, B-cell lymphoma 2 (Bcl-2), nuclear factor (NF)- $\kappa \mathrm{B}$, and early growth response protein 1 (Egr-1), which are central in cellular activities and have been demonstrated to be responsible for radioresistance in human tissues $(16,17)$. The present study aimed to identify whether changes in the mRNA expression levels of these genes may serve as potential prognostic markers of early-stage hypothyroidism induced by iodine-131 treatment.

\section{Patients and methods}

Patients and tissue samples. This present case-cohort study featured a case cohort and a comparison cohort. A total of 59 patients diagnosed with hyperthyroidism at the First Affiliated Hospital of Xi'an Jiao Tong University (Xi'an, China) were randomly selected for the present study between May and October 2013. Hyperthyroidism was diagnosed on the basis of the following: i) High metabolic syndrome including increased heart rate, sudden weight loss or nervousness, enlarged thyroid gland, hand shaking or swelling or inflammation around eyes; ii) increased free thyroid hormones, decreased sensitive thyroid-stimulating hormone (sTSH) and elevated iodine-131 uptake by the thyroid. Prior to treatment, multiple indices were measured, including serum thyroid hormone levels, thyroid antibody levels, and a routine blood test (2 ml samples), liver and kidney function test, and electrocardiograph were performed in order to evaluate the physical condition of the patients. This was operated by the laboratory professionals (using radioimmunoassay). All patients were asked to avoid consuming seafood and drugs that may affect iodine-131 uptake 1 week prior to treatment until 3 months following treatment. Patients were not included in the present study if they presented with any of the following: i) Aged $\leq 12$ years; ii) pregnant and lactating; (iii) presence of thyroid nodules that may be malignant; iv) history of thyroidectomy. Patients were treated with iodine-131 (Chengdu Gaotong Isotope Co., Ltd., Sichuan, China) orally in a capsule form, and the doses were calculated according to the formula described by Marinelli et al (18). Early-stage hypothyroidism assessment was performed 3 months following iodine-131 treatment by evaluating the levels of sTSH and thyroid hormone. The patients were divided into two groups: An early-stage hypothyroidism group, including subclinical hypothyroidism; and a non-early-stage hypothyroidism group, including euthyroid and hyperthyroid patients.

The comparison cohort included 27 healthy volunteers. No selected subject had been diagnosed with hyperthyroidism. All fine needle thyroid tissue specimens, including those of patients with hyperthyroidism and healthy volunteers, were collected according to the procedures approved by the Human Ethics Committee of the Xi'an Medical University, and all patients and control subjects provided written informed consent.

$m R N A$ purification and reverse transcription-quantitative polymerase chain reaction $(R T-q P C R)$ analysis. Total RNA was extracted from the biopsy tissue samples using TRIzol ${ }^{\circledR}$ reagent (Invitrogen Life Technologies, Carlsbad, CA, USA), according to the manufacturer's instructions. The concentration of the purified total RNA was measured using a Nanodrop 1000 ultraviolet spectrophotometer (Thermo Fisher Scientific, Wilmington, DE, USA) and the optical density 260/280 ratios were between 1.8-2.0. Total RNA was reverse transcribed into cDNA using QTM SYBR ${ }^{\circledR}$ Green Supermix (Bio-Rad Laboratories, Inc., Hercules, CA, USA) in a $10 \mu \mathrm{l}$ reaction system containing $500 \mathrm{ng}$ total RNA. The thermocycling conditions were as follows: $15 \mathrm{~min}$ at $37^{\circ} \mathrm{C}$ and $5 \mathrm{sec}$ at $85^{\circ} \mathrm{C}$. Quantification of the copy number was performed using qPCR with $\beta$-actin gene as the internal reference. qPCR was performed in a $20 \mu 1$ volume system containing $2 \mu \mathrm{l} \mathrm{cDNA,} 12.5 \mu \mathrm{l} \mathrm{SYBR}{ }^{\circledR}$ Premix Ex Taq Um ${ }^{\mathrm{TM}} \mathrm{II}$ (Takara Biotechnology, Co., Ltd., Dalian, China), $1 \mu$ l forward

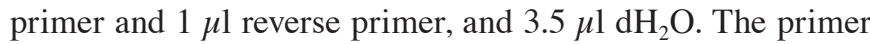
sequences of targeted genes and $\beta$-actin are presented in Table I. Primers were obtained from Takara Biotechnology, Co., Ltd. The thermocycling conditions were as follows: $15 \mathrm{sec}$ at $95^{\circ} \mathrm{C}, 30 \mathrm{sec}$ at $60^{\circ} \mathrm{C}$ and $30 \mathrm{sec}$ at $72^{\circ} \mathrm{C}$ for 40 cycles following an initial activating step for $2 \mathrm{sec}$ at $50^{\circ} \mathrm{C}$, and a denaturing step for $10 \mathrm{~min}$ at $95^{\circ} \mathrm{C}$. A Bio-Rad CFX Manager thermal Cycler Dice ${ }^{\mathrm{TM}}$ real time PCR system was used (Bio-Rad Laboroatories, Inc.). The relative copy number of target genes was measured using the $2^{-\Delta \Delta \mathrm{Ct}}$ method (19). $\beta$-actin was used as 
Table I. Primer sequences of the target genes and $\beta$-actin for reverse transcription-quantitative polymerase chain reaction.

\begin{tabular}{|c|c|c|c|}
\hline Gene & Sense & Antisense & $\begin{array}{c}\text { Product size } \\
\text { (bp) }\end{array}$ \\
\hline p53 & 5'-CTCCTCAGCATCTTACCGAGT-3' & 5'-GCTGTTCCGTCCCAGTAGATTA-3' & 239 \\
\hline Bcl-2 & 5'-ATGTGTTGGAGAGCGTCAAC-3' & 5'-AGAGACAGCCAGGAGAAATCAAAC-3' & 182 \\
\hline EGFR & 5'-ATCATACGCGGCAGGACCA-3' & 5'-TCTGACCGGAGGTCCCAAAC-3' & 187 \\
\hline Egr-1 & 5'-AGAGCATGTGTCAGAGTGTTGTTCC-3' & 5'-CACATGTCAAGCCATCAGCAAG-3' & 196 \\
\hline $\mathrm{Ku} 70$ & 5'-GCAACCAGAAGTGCCAGCTTA-3' & 5'-TGAGTGTTTCATAGCATCAAGCAGA-3' & 86 \\
\hline $\mathrm{NF}-\kappa \mathrm{B}$ & 5'-TGGCGCAGAAATTAGGTCTGG-3' & 5'-GATCACTTCAATTGCTTCGGTGTA-3' & 161 \\
\hline ATM & 5'-TGTGACTTTTCAGGGGATTTG-3' & 5'-ATAGGAATCAGGGCTTTTGGA-3' & 121 \\
\hline$\beta$-actin & 5'-ACGAGGCCCAGAGCAAGAGA-3' & 5'-GGTCTTTGCGGATGTCCACG-3' & 96 \\
\hline
\end{tabular}

Bcl-2, B-cell lymphoma 2; EGFR, epidermal growth factor receptor; Egr-1, early growth response 1; NF- $\kappa$ B, nuclear factor $\kappa$ B; ATM, ataxia telangiectasia mutated.

Table II. Variables and constants in the logistic resection equation.

\begin{tabular}{lcccccc}
\hline Factor & B & SE & HR & P-value & CI (RC) 95\% lower & CI (RC) 95\% upper \\
\hline Variable & & & & & 0.102 & 0.909 \\
NF-אB & -0.819 & 0.748 & 0.200 & 0.273 & 0.086 & 0.747 \\
Bcl-2 & -1.373 & 0.552 & 6.193 & 0.013 & 1.106 & 2.197 \\
Egr-1 & 0.444 & 0.175 & 6.432 & 0.011 & & \\
Constant & -0.156 & 0.628 & 0.062 & 0.804 & \\
\hline
\end{tabular}

$\mathrm{B}$, regression coefficient; SE, standard error; HR, hazard ratio; CI, confidence interval; RC, regression coefficient; NF- $\kappa \mathrm{B}$, nuclear factor $\kappa \mathrm{B}$; Bcl-2, B-cell lymphoma 2; Egr-1, early growth response 1.

an endogenous reference and each sample was repeated twice, with the mean values calculated for statistical analysis.

Statistical analysis. Statistical significance was examined using Student's t-test for comparison between two different groups. $\mathrm{P}<0.05$ was considered to indicate a statistically significant difference when comparing two groups. Correlation between the changes in mRNA expression and the susceptibility of early-stage hypothyroidism was examined using multivariate logistic regression analysis. The level of gene expression was presented as mean \pm standard deviation. All statistical analyses were performed using SPSS 17.0 (SPSS, Inc., Chicago, IL, USA), and the type I error was set at $5 \%$.

\section{Results}

mRNA expression levels of target genes in patients with hyperthyroidism and normal healthy subjects. A total of 59 patients diagnosed with hyperthyroidism and 27 healthy subjects were included in the present study. To measure the mRNA expression levels of the selected target genes, seven sets of primers were designed, based on the National Center for Biotechnology database (http://www.ncbi.nlm.nih.gov/), and a pair of primers was designed for $\beta$-actin as an endogenous reference to normalize the expression levels of genes. Using fine needle biopsy, tissue samples from all patients (pre-treat- ment group) and volunteers (control group) were collected, and total the mRNA from each sample were extracted and reverse transcribed into cDNA. The cDNA products were then amplified using qPCR, followed by quantification of the mRNA expression levels using Bio-Rad CFX Manager. Compared with the control group, the mRNA expression levels of Ku70 and EGFR were significantly higher, and those of TP53 were marginally higher in patients with hyperthyroidism; however, the mRNA expression levels of Bcl-2, NF- $\kappa \mathrm{B}$ and Egr-1 were markedly lower, and those of ATM were marginally lower in the patients with hyperthyroidism, compared with the healthy control group (Fig. 1). Furthermore, regression analysis demonstrated that the mRNA expression levels of Bcl-2 and $\mathrm{NF}-\kappa \mathrm{B}$ were associated $(\mathrm{R}=0.399 ; \mathrm{P}<0.001$; Fig. 2$)$ in the samples of patients with hyperthyroidism (Fig. 2).

Comparison of target $m R N A$ expression levels in early and non-early-stage hypothyroidism. Iodine-131 was administered orally to all patients, the dose of which was to the previously a formula previously described by Marinelli et al (18). At 3 months post-treatment, the serum indices were measured, and 30 patients were identified with early-stage hypothyroidism symptoms, including decreased levels of FTH and increased levels of sTSH (including subclinical hypothyroidism). Subsequently, the 59 patients were divided into an early-hypothyroidism group, which included the 30 patients 

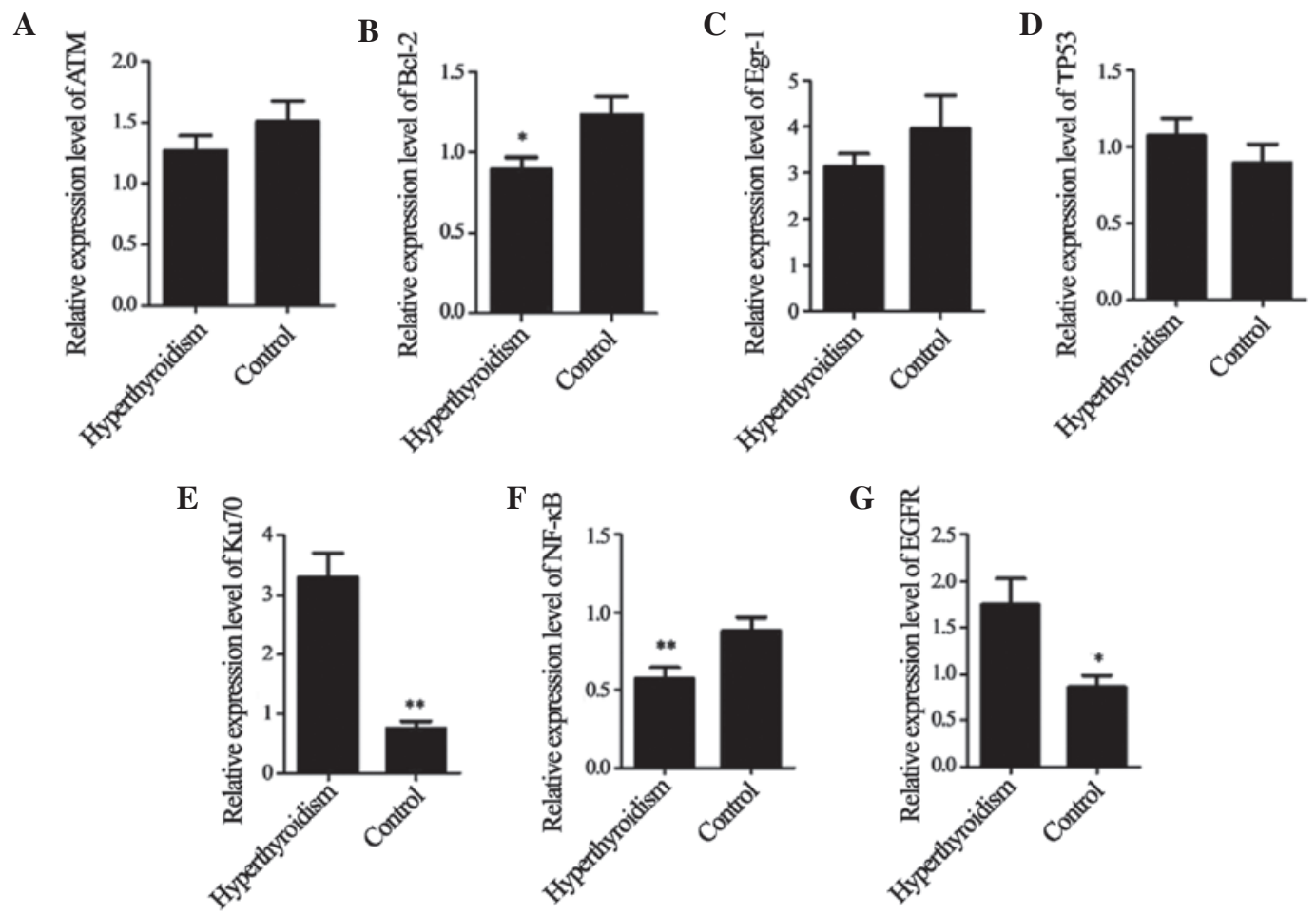

Figure 1. Mean mRNA expression levels of target genes in the hyperthyroidism and control groups. The relative mRNA expression levels of (A) ATM, (B) Bcl-2, (C) Egr-1, (D) TP53, (E) Ku70, (F) NF- - B and (G) EGFR. "P<0.05, and " $\mathrm{P}<0.01$, vs. control group. ATM, ataxia telangiectasia mutated; Bcl-2, B-cell lymphoma 2; Egr-1, early growth response 1; NF- $\mathrm{B}$, nuclear factor $\kappa \mathrm{B}$; EGFR, epidermal growth factor receptor.

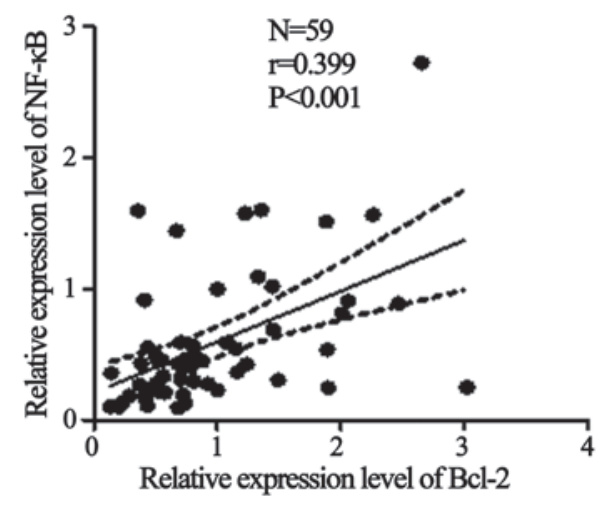

Figure 2. Relative mRNA expression levels of Bcl-2 and NF- $\mathrm{KB}$ in 59 patients with hyperthyroidism $(\mathrm{r}=0.399 ; \mathrm{P}<0.001)$. Bcl-2, B-cell lymphoma 2 ; NF- $\mathrm{kB}$, nuclear factor $\kappa \mathrm{B}$. Line shows correlation between $\mathrm{Bcl}-2$ and $\mathrm{NF}-\kappa \mathrm{B}$; dashed line shows confidence interval.

with symptoms of hypothyroidism; and a non-early-stage hypothyroidism group, which included the remaining 29 patients who continued to exhibit hyperthyroidism. The mRNA expression levels of the target genes in the groups were then investigated. Notably, among the target genes, the mRNA expression levels of $\mathrm{Bcl}-2$ were significantly lower in the patients of the early-hypothyroidism group, compared with the patients of the non-early-stage hypothyroidism group, and these expression levels were even lower than those of the patients of the pre-treatment and control groups (Fig. 3A). This suggested that the decrease in the expression of Bcl-2 mRNA may be associated with the onset of early-stage hypothyroidism. In addition to $\mathrm{Bcl}-2$, distinct changes in the mRNA expression levels of Egr-1 were observed. The mRNA expression levels of Egr-1 were markedly increased in the early-hypothyroidism group, compared with the non-early-stage hypothyroidism group, and these expression levels were comparable to those in the control group (Fig. 3B). Although the present study did not provide further experimental data to address the potential significance of the increase in Egr-1 expression levels in patients with hypothyroidism, the association between Egr-1 and hypothyroidism merits further research. Notably, the mRNA expression levels of Ku70 and EGFR which were high in the pre-treatment group maintained these high levels in the early-hypothyroidism and non-early-stage hypothyroidism groups, which suggested that the increase was likely to be associated with the initiation of hyperthyroidism (Fig. 4A and B). However, the mRNA expression levels of the other genes, including ATM, TP53 and NF- $\kappa \mathrm{B}$ exhibited only marginal differences between the groups (Fig. 4C-E).

mRNA expression levels of Bcl-2 and Egr-1 are associated with susceptibility to hypothyroidism. The present study further investigated whether the changes in mRNA expression levels were associated with susceptibility to hypothyroidism through a multiple logistic regression model. The statistical differences in the mRNA expression levels of ATM, TP53, EGFR, NF- $\kappa \mathrm{B}$ and Ku70 were not significant between the early-stage hypothyroidism group and the non-early-stage hypothyroidism group. However, the model revealed that the regression coefficient of Egr-1 [hazard ration (HR), 6.432; 95\% CI, 1.106-2.197] and Bcl-2 (HR, 6.193; 95\% CI, 0.086-0.747) were positively and negatively correlated with the occurrence of early-stage hypothyroidism, respectively (Table II). These results suggested that increasing the expression of Egr-1 is likely to increase the likelihood of developing early-hypothy- 
A

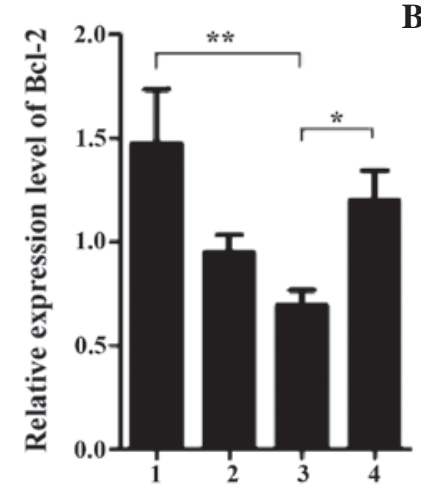

B

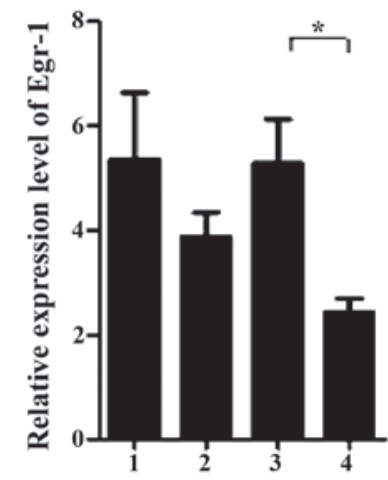

Figure 3. Mean mRNA expression levels of target genes in the (1) control group, (2) hyperthyroidism group, (3) early-hypothyroidism group and (4) non-early-stage hypothyroidism group. Relative mRNA expression levels of (A) Bcl-2, (B) Egr-1. ${ }^{*} \mathrm{P}<0.05$ and ${ }^{* *} \mathrm{P}<0.01$. Bcl-2, B-cell lymphoma 2; Egr-1, early growth response 1; EGFR, epidermal growth factor receptor.

A

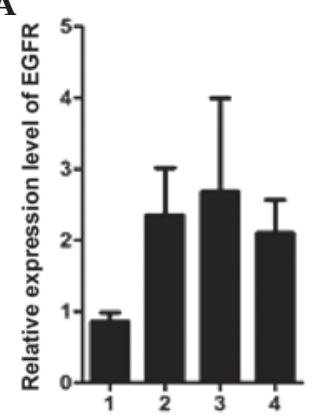

C

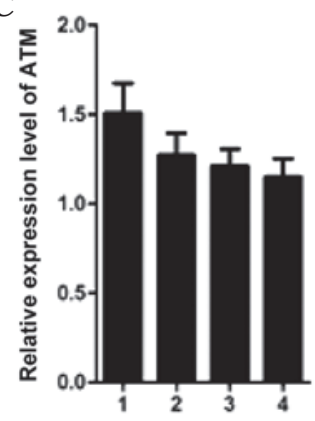

B

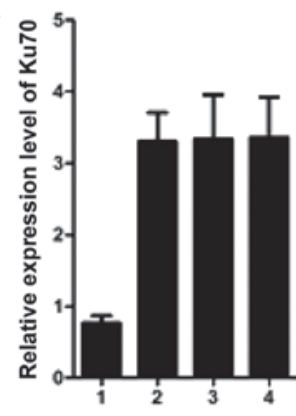

D

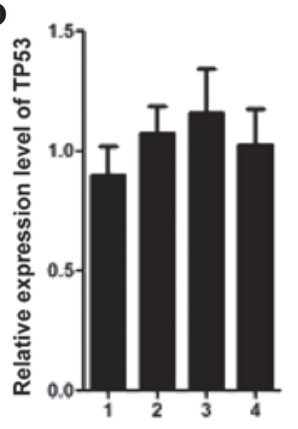

$\mathbf{E}$

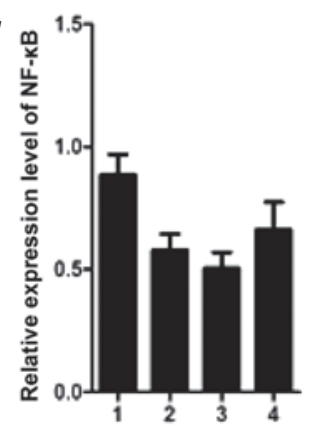

Figure 4. Mean mRNA expression levels of target genes in the (1) control group, (2) hyperthyroidism group, (3) early hypothyroidism group and (4) non-early-stage hypothyroidism group. Relative mRNA expression levels of (A) EGFR, (B) Ku70, (C) ATM, (D) TP53 and (E) NF- $\mathrm{B}$. EGFR, epidermal growth factor receptor; NF- $\kappa \mathrm{B}$, nuclear factor $\kappa \mathrm{B}$.

roidism, whereas the susceptibility to early-hypothyroidism is likely to be reduced if the expression of Bcl-2 is suppressed.

\section{Discussion}

It has long been recognized that each human disease has an underlying molecular mechanism, and the elucidation of these mechanisms is directly associated with the understanding of the cause, process and treatment of these diseases. Of numerous strategies, the identification of susceptible genes with expression levels, which are significantly altered in patients is one of the most widely used methods to investigate the basis of diseases in humans. Hyperthyroidism is one of most common autoimmune thyroid diseases, and several genes, including thyroid stimulating hormone receptor and thyroglobulin, which belong to thyroid-specific genes; and human leukocyte antigen (HLA) class II, cytotoxic T-lymphocyte-associated protein 4 and PTPN22, which belong to immunoregulatory genes, have been identified and recognized as risk factors of hypothyroidism (4). Other genes, including HLA class I, HLA-C, HLA-B, CD40 and Fc receptor-like 3 have also been subsequently identified, which has provided insight into the molecular mechanisms underlying the immunopathogenesis of hyperthyroidism (4). Iodine-131 is currently the predominant drug used to treat hyperthyroidism, and one of side-effects, hypothyroidism, is almost always associated with this treatment strategy $(6,20-23)$. However, to the best of our knowledge, the unstable gene expression, which may be associated with hypothyroidism has not been investigated. As iodine-131 treatment induces genomic damage, 
demonstrated by the previous observation of increased micronuclei, and differences in individual radiosensitivity regulated by specific genes are the predominant factors that affect the efficacy of iodine-131 treatment (24), the present study hypothesized that radioresistant/radiosensitive and/or cell proliferation-associated genes may be involved in the pathologic process of iodine-131-dependent hypothyroidism. Several genes, including EGFR, ATM, TP53, Ku70, Bcl-2, $\mathrm{NF}-\kappa \mathrm{B}$ and Egr-1, were selected in the present study, and their mRNA expression levels were quantified. Irradiation-induced DNA double strand breaks (DSBs) are the most life-threatening form of DNA damage, and ATM, Ku70 and TP53 are important in the DSB responses (25). ATM is recruited to DSB sites in the initial stage of DNA damage response and is activated through the phosphorylation of serine 1981 (26). This activated ATM then amplifies the DNA damage signal by recruiting more substrates to facilitate DNA repair. $\mathrm{Ku} 70$, initially described as an auto-antigen in the blood of patients with systemic lupus erythematosus, forms heterodimers with Ku80 (27) and functions in DNA damage repair via the non-homologous end joining (NHEJ)-mediated signaling pathway (28). NHEJ is also required for antigen receptor gene rearrangements and the development of $\mathrm{T}$ and $\mathrm{B}$ cells in the vertebrate immune system (29). TP53 is a major downstream effector in the DNA damage signaling cascade, and the activation of TP53 is required for DNA damage-induced cell cycle arrest, as well as apoptosis if the DSBs are too severe to be repaired (30). Our previous study demonstrated that neither the mRNA nor protein expression levels of TP53 are altered in response to iodine-131 exposure (31). In the present study, the mRNA expression levels of ATM and TP53 were found to be sustained in patients with hyperthyroidism and the control group, whereas the mRNA expression levels of Ku70 increased markedly in the tissue samples of the patients with hyperthyroidism. However, the mRNA expression levels of the three targets were not significantly different between the early-stage hyperthyroidism and non-early-stage hyperthyroidism groups. However, the specific increase in the mRNA expression of Ku70 in patients, irrespective of iodine-131 treatment, indicated that $\mathrm{Ku} 70$ is likely a potential risk factor for hyperthyroidism.

Previous studies demonstrated that EGFR is required for thyroid growth as one of the membrane fractions of thyroid cells in normal and neoplastic tissues of various organs (32-34). EGFR increases the proliferation of cultured dog thyroid cells, and enhances the DNA synthesis in cultured porcine thyroid cells (35). In addition, significantly increased expression levels of EGFR have been reported in malignant thyroid tissue samples (36). The present study demonstrated that the mRNA expression levels of EGFR were significantly increased in patients with hyperthyroidism, which is concordant with the observations described by Marti et al (37), in which that nuclear expression of EGFR was enhanced in tissue samples of patients with Graves disease and goiter, compared with normal thyroid tissue samples. This indicates that the EGFR-dependent regulation of thyroid cell proliferation under pathological conditions may be associated with hyperthyroidism. However, the mRNA expression levels of EGFR remained unchanged following treatment with iodine-131.
$\mathrm{NF}-\kappa \mathrm{B}$ is involved in the signaling pathway of immune and inflammatory responses (38). Nandakumar et al (39) demonstrated that $\mathrm{NF}-\kappa \mathrm{B}$ is activated patients with hyperthyroidism. Vinayagamoorthi et al (40) also demonstrated that the NF- $\mathrm{NB}$ signaling pathway is activated in lymphocytes in an L-thyroxin-treated hyperthyroid rat model. The present study demonstrated that the mRNA expression levels of $\mathrm{NF}-\kappa \mathrm{B}$ were significantly lower in patients with hyperthyroidism, compared with control subjects, which is concordant with the results of a previous study by Kumar et al (41), who reported that triiodothyronine treatment activated $\mathrm{NF}-\kappa \mathrm{B}$, however, protein expression levels of $\mathrm{NF}-\kappa \mathrm{B}$ were downregulated in response to persistent exposure (10 days) to triiodothyronine. Several studies have also demonstrated that NF- $\mathrm{NB}$ negatively regulates apoptosis by upregulating the expression of anti-apoptotic Bcl-2 (42-44); and Bcl-2 is involved in the selection and maintenance of long-lived memory $\mathrm{T}$ cells (45). Bcl-2 protein expression levels are decreased in hyperthyroid rats (46) and in the lymphocytes of patients with hyperthyroidism (47). The results of the present study also demonstrated that the mRNA expression of Bcl-2 was significantly lower in patients with hyperthyroidism, compared with healthy subjects, and this downregulation was positively correlated with a decrease in the expression of $\mathrm{NF}-\kappa \mathrm{B}$, determined using the simple regression analysis. These data suggested that $\mathrm{NF}-\kappa \mathrm{B}$ and Bcl-2-mediated apoptosis may be involved in the onset of hyperthyroidism through disorder of immune responses. However, the mRNA expression levels of Bcl-2, but not $\mathrm{NF}-\kappa \mathrm{B}$, further decreased in patients with iodine-131 therapy-induced early-stage hypothyroidism. In addition to the significant decrease in the expression of Bcl-2, higher mRNA expression levels of Egr-1 were detected in the tissue samples of patients with early-stage hypothyroidism, compared with the non-early-stage hypothyroidism group. Bcl-2 and Egr-1 are anti-apoptotic and pro-apoptotic genes, respectively, and the opposing changes in mRNA expression levels of the two genes in the early-stage hypothyroidism group suggested that dysregulation of apoptosis is a significant causative factor in hypothyroidism. Following stepwise-selected multivariate regression analysis of the seven gene targets, only Bcl-2 and Egr-1 exhibited characteristics as independent prognostic factors in early-stage hypothyroidism.

In conclusion, the results of the present study demonstrated that the mRNA expression levels of Ku70 and EGFR were markedly increased, whereas those of NF- $\kappa \mathrm{B}$ and $\mathrm{Bcl}-2$ were decreased in the tissue samples of patients with hyperthyroidism. The mRNA expression levels of NF- $\kappa \mathrm{B}$ changed marginally, whereas those of Bcl-2 decreased further in the early-stage hypothyroidism group in response to iodine-131 treatment. In addition, the expression levels of Bcl-2 and Egr-1 were altered in an opposing manner in the early-hypothyroidism group, compared with the non-early-stage hypothyroidism group and hyperthyroidism group. Stepwise-selected multivariate regression analysis indicated that Bcl-2 and Egr-1 may serve as prognostic markers of early-stage hypothyroidism. However, the molecular mechanism underlying the association between changes in mRNA expression and the initiation of hyperthyroidism/hypothyroidism requires further investigation. 


\section{Acknowledgements}

The authors of the present study would like to thank Professor Bingyin Shi and the staff of the Nuclear Medicine Department of The First Affiliated Hospital of Xi'an Jiaotong University College of Medicine (Xi'an, China) for their support. The present study was supported by the National Natural Science Foundation of China (grant no. 81172598).

\section{References}

1. Bahn Chair RS, Burch HB, Cooper DS, Garber JR, Greenlee MC, Klein I, Laurberg P, McDougall IR, Montori VM, Rivkees SA, et al; American Thyroid Association; American Association of Clinical Endocrinologists: Hyperthyroidism and other causes of thyrotoxicosis: management guidelines of the American Thyroid Association and American Association of Clinical Endocrinologists. Thyroid 21: 593-646, 2011.

2. Vanderpump MP, Tunbridge WM, French JM, Appleton D, Bates D, Clark F, Grimley Evans J, Hasan DM, Rodgers H, Tunbridge F, et al: The incidence of thyroid disorders in the community: A twenty-year follow-up of the Whickham survey. Clin Endocrinol (Oxf) 43: 55-68, 1995.

3. Klein I and Ojamaa K: Thyroid hormone and the cardiovascular system. N Engl J Med 344: 501-509, 2001.

4. Effraimidis G and Wiersinga WM: Mechanisms in endocrinology: Autoimmune thyroid disease: Old and new players. Eur J Endocrinol 170: R241-R252, 2014.

5. Solomon B, Glinoer D, Lagasse R and Wartofsky L: Current trends in the management of Graves' disease. J Clin Endocrinol Metab 70: 1518-1524, 1990

6. Wartofsky L, Glinoer D, Solomon B, Nagataki S, Lagasse R, Nagayama Y and Izumi M: Differences and similarities in the diagnosis and treatment of Graves' disease in Europe, Japan and the united states. Thyroid 1: 129-135, 1991.

7. Kraft O: Hypothyroidism and radioiodine therapy. Cancer Biother Radiopharm 22: 261-267, 2007.

8. Berg GE, Michanek AM, Holmberg EC and Fink M: Iodine-131 treatment of hyperthyroidism: Significance of effective half-life measurements. J Nucl Med 37: 228-232, 1996.

9. Catargi B, Leprat F, Guyot M, Valli N, Ducassou D and Tabarin A: Optimized radioiodine therapy of Graves' disease: Analysis of the delivered dose and of other possible factors affecting outcome. Eur J Endocrinol 141: 117-121, 1999.

10. de Jong JA, Verkooijen HM, Valk GD, Zelissen PM and de Keizer B: High failure rates after 131I therapy in graves hyperthyroidism patients with large thyroid volumes, high iodine uptake and high iodine turnover. Clin Nucl Med 38: 401-406, 2013.

11. Anai S, Shiverick K, Medrano T, Nakamura K, Goodison S, Brown BD and Rosser CJ: Downregulation of BCL-2 induces downregulation of carbonicanhydrase IX, vascular endothelial growth factor and pAkt and induces radiation sensitization. Urology 70: 832-837, 2007.

12. Schneider J, Illig T, Rosenberger A, Bickeböller H and Wichmann HE: Detection of atm gene mutations in young lung cancer patients: A population-based control study. Arch Med Res 39: 226-231, 2008.

13. Kiyozuka M, Akimoto T, Fukutome M, Motegi A and Mitsuhashi N: Radiation-induced dimer formation of EGFR: Implications for the radiosensitizing effect of cetuximab. Anticancer Res 33: 4337-4346, 2013.

14. Akimoto T, Hunter NR, Buchmiller L, Mason K, Ang KK and Milas L: Inverse relationship between epidermal growth factor receptor expression and radiocurability of murine carcinomas. Clin Cancer Res 5: 2884-2890, 1999.

15. Vera-Badillo FE, Al-Mubarak M, Templeton AJ and Amir E: Benefit and harms of new anti-cancer drugs. Curr Oncol Rep 15 270-275, 2013.

16. Ahmed MM, Venkatasubbarao K, Fruitwala SM, MuthukkumarS, Wood DP Jr, Sells SF, Mohiuddin M and Rangnekar VM: EGR-1 induction is required for maximal radiosensitivity in A375-C6 melanoma cells. J Biol Chem 271: 29231-29237, 1996.

17. Zagurovskaya M, Shareef MM, Das A, Reeves A, Gupta S, Sudol M, Bedford MT, Prichard J, Mohiuddin M and Ahmed MM: EGR-1 forms a complex with YAP-1 and upregulates Bax expression in irradiated prostate carcinoma cells. Oncogene 28: 1121-1131, 2009.
18. Marinelli LD, Quimby EH and Hine GJ: Dosage determination with radioactive isotopes. Nucleonics 2: 56, 1948.

19. Zhang W, Gao R, Yu Y, Guo K, Hou P, Yu M, Liu Y and Yang A: Iodine-131 induces apoptosis in HTori-3 human thyrocyte cell line and $\mathrm{G} 2 / \mathrm{M}$ phase arrest in a p53-independent pathway. Mol Med Rep 11: 3148-3154, 2015.

20. Erem C, Kandemir N, Hacihasanoglu A, Ersöz HO, Ukinc K and Kocak M: Radioiodine treatment of hyperthyroidism: prognostic factors affecting outcome. Endocrine 25: 55-60, 2004

21. Vaidya B, Williams GR, Abraham P and Pearce SH: Radioiodine treatment for benign thyroid disorders: results of a nationwide survey of UK endocrinologists. Clin Endocrinol (Oxf) 68: 814-820, 2008

22. Nygarrd B, Hegedüs L, Gervil M, Hjalgrim H, Hansen BM, Søe-Jensen $\mathrm{P}$ and Hansen JM: Influence of compensated radioiodine therapy on thyroid volume and incidence of hypothyroidism in Graves' disease. J Intern Med 238: 491-497, 1995.

23. Sridama V, McCormick M, Kaplan EL, Fauchet R and DeGroot LJ. Long-term follow-up study of compensated low-dose 131I therapy for Graves' disease. N Engl J Med 311: 426-432, 1984 .

24. Farkasova T, Gurska S, Witkovsky V and Gabelova A Significance of amino acid substitution variants of DNA repair genes in radiosusceptibility of cervical cancer patients; a pilot study. Neoplasma 55: 330-337, 2008.

25. Krempler A, Deckbar D, Jeggo PA and Löbrich M. An imperfect G2M checkpoint contributes to chromosome instability following irradiation of S and G2 phase cells. Cell Cycle 6: 1682-1686, 2007.

26. Darzynkiewicz Z, Zhao H, Halicka HD, Rybak P, Dobrucki J and Wlodkowic D: DNA damage signaling assessed in individual cells in relation to the cell cycle phase and induction of apoptosis. Crit Rev Clin Lab Sci 49: 199-217, 2012.

27. Mimori T, Akizuki M, Yamagata H, Inada S, Yoshida S and Homma M: Characterization of a high molecular weight acidic nuclear protein recognized by autoantibodies in sera from patients with polymyositis-scleroderma overlap. J Clin Invest 68: 611-620, 1981.

28. Dobbs TA, Tainer JA and Lees-Miller SP: A structural model for regulation of NHEJ by DNA-PKcs autophosphorylation. DNA Repair (Amst) 9: 1307-1314, 2010.

29. Helmink BA and Sleckman BP: The response to and repair of RAG-mediated DNA double-strand breaks. Annu Rev Immunol 30: 175-202, 2012.

30. Otsuka K and Ochiya T. Genetic networks lead and follow tumor development: microRNA regulation of cell cycle and apoptosis in the p53 pathways. Biomed Res Int 2014: 749724, 2014.

31. Weixiao Z, Rui G, Yan Y, Kun G, Peng H, Yan L and Mingqi Y: Iodine-131 induces apoptosis in the HTori 3 cell line and G2/M arrest in a p53-independent pathway. Mol Med Rep 11:3148-3154, 2015.

32. Kasai K, Kuroda H, Hashigami Y, Ishikawa M, Nakamura T and Shimoda SI: Specific epidermal growth factor receptors on porcine and human thyroid membranes. Horm Metab Res 17: 592-594, 1985.

33. Kanamori A, Abe Y, Yajima Y, Manabe Y and Ito K: Epidermal growth factor receptors in plasma membranes of normal and diseased human thyroid glands. J Clin Endocrinol Metab 68: 899-903, 1989.

34. Saller B, Stapfer G, Bein B, Hoermann R, Spelsberg F and Mann K: Increased binding capacity of receptors for the epidermal growth factor in benign thyroid nodules and thyroid malignancies. Clin Investig 71: 898-902, 1993.

35. Westermark K, Karlsson FA and Westermark B: Epidermal growth factor modulates thyroid growth and function in culture. Endocrinology 112: 1680-1686, 1983.

36. Mizukami Y, Nonomura A, Michigishi T, Yokoyama K, Noguchi M, Hashimoto T, Nakamura $S$ and Matsubara F: Immunohistochemical demonstration of epidermal growth-factor receptors in normal, benign and malignant thyroid tissues. Int J Oncol 1: 331-335, 1992.

37. Marti U, Ruchti C, Kämpf J, Thomas GA, Williams ED, Peter HJ, Gerber H and Bürgi U: Nuclear localization of epidermal growth factor and epidermal growth factor receptors in human thyroid tissues. Thyroid 11: 137-145, 2001.

38. Aggarwal BB, Takada Y, Shishodia S, Gutierrez AM, Oommen OV, Ichikawa H, Baba Y and Kumar A: Nuclear transcription factor NF-kappa B: Role in biology and medicine. Indian J Exp Biol 42: 341-353, 2004 
39. Nandakumar DN, Koner BC, Vinayagamoorthi R, Nanda N, Negi VS, Goswami K, Bobby Z and Hamide A: Activation of NF-kappaB in lymphocytes and increase in serum immunoglobulin in hyperthyroidism: Possible role of oxidative stress. Immunobiology 213: 409-415, 2008.

40. Vinayagamoorthi R, Koner BC, Kavitha S, Nandakumar DN, Padma Priya P and Goswami K: Potentiation of humoral immune response and activation of NF-kappaB pathway in lymphocytes in experimentally induced hyperthyroid rats. Cell Immunol 238: 56-60, 2005.

41. Kumar A, Sinha RA, Tiwari M, Singh R, Koji T, Manhas N, Rastogi L, Pal L, Shrivastava A, Sahu RP and Godbole MM: Hyperthyroidism induces apoptosis in rat liver through activation of death receptor-mediated pathways. J Hepatol 46: 888-898, 2007.

42. Chen F, Castranova V and Shi X: New insights into the role of nuclear factor-kappaB in cell growth regulation. Am J Pathol 159: 387-397, 2001.
43. Mattson MP and Camandola S. NF- $\kappa$ B in neuronal plasticity and neurodegenerative disorders. J Clin Invest 107: 247-254, 2001.

44. Chen C, Edelstein LC and Gelinas C: The Rel/ NF-kappaB family directly activates expression of the apoptosis inhibitor Bcl-x(L). Mol Cell Biol 20: 2687-2695, 2000.

45. Czabotar PE, Lessene G, Strasser A and Adams JM: Control of apoptosis by the BCL-2 protein family: Implications for physiology and therapy. Nat Rev Mol Cell Biol 15: 49-63, 2014.

46. Klatka M, Grywalska E, Polak A and Roliński J: Impact of treatment with methimazole on the Bcl-2 expression in CD8+ peripheral blood lymphocytes in children with Graves' disease. Ann Agric Environ Med 20: 884-888, 2013.

47. Giriş M,Erbil Y, Depboylu B, Mete O, Türkoğlu U, Abbasoğlu SD and Uysal M: Heme oxygenase-1 prevents hyperthyroidism induced hepatic damage via an antioxidant and antiapoptotic pathway. J Surg Res 164: 266-275, 2010. 